\title{
Uso do sistema teste de Allium cepa como bioindicador de genotoxicidade de infusões de plantas medicinais
}

\author{
Margarete Dulce Bagatini', Antonio Carlos Ferreira da Silva ${ }^{2}$, Solange Bosio Tedesco ${ }^{2 *}$ \\ ${ }^{1}$ Curso de Farmácia, Universidade Federal de Santa Maria, Av. Roraima 1000, Cidade Universitária, Camobi, \\ 97105-900, Santa Maria, RS, Brasil, \\ ${ }^{2}$ Laboratório de Citogenética Vegetal, Departamento de Biologia, Universidade Federal de Santa Maria, \\ Av. Roraima 1000, Cidade Universitária, Camobi, 97105-900, Santa Maria, RS, Brasil
}

\begin{abstract}
RESUMO: Mundialmente, muitas espécies de plantas medicinais são utilizadas para o tratamento de doenças. No entanto, a maioria dessas espécies não foram suficientemente estudadas, principalmente quanto à presença de substâncias citotóxicas/mutagênicas em sua composição ou decorrentes do próprio metabolismo e podem causar danos à saúde da população. A presença de substâncias mutagênicas nas espécies vegetais que causam alterações cromossômicas podem ser detectadas durante o ciclo celular de uma espécie. O sistema teste de Allium cepa é freqüentemente utilizado para avaliação do potencial genotóxico de extratos de plantas medicinais através da análise de células meristemáticas provenientes de pontas de raízes tratadas com infusões medicinais (chás). O conhecimento do potencial genotóxico destas espécies medicinais, através da análise do ciclo celular de Allium cepa serve como indicativo de segurança para a população que utiliza chás medicinais como única alternativa para o tratamento de doenças. Essa revisão, objetiva informar a respeito da importância do teste de Allium cepa para avaliação preliminar da genotoxicidade de infusões de plantas medicinais.
\end{abstract}

Unitermos: Allium cepa, plantas medicinais, citotoxicidade, mutagenicidade.

\begin{abstract}
The use of Allium cepa test as a bioindicator of genotoxicity of medicinal plants infusions". All over the world, many species of medicinal plants are used for disease treatments. However, most of them were not deeply studied; and the presence of cytotoxic or mutagenic substances in their composition or resulting from their metabolism may be harmful to human beings. The mutagenic effects caused by such substances result in chromosomal changes which are detecTable during the cell cycle of a species through cytogenetic analysis. The Allium cepa test system is widely used for evaluating the genotoxic potential of infusions (tea) made of medicinal plants, through the cell cycle analysis. The knowledge of the genotoxic potential of such species through the Allium cepa test serves as a warning and safety bioindicator for the population who uses medicinal tea quite often as the unique alternative for disease treatment of its people. In the review article, we intend to inform people about the importance of the Allium cepa test for evaluating the genotoxicity of infusions of medicinal plants.
\end{abstract}

Keywords: Allium cepa, medicinal plants, cytotoxicity, mutagenicity.

\section{INTRODUÇÃO}

As plantas medicinais são utilizadas mundialmente para o tratamento de doenças, e a maioria delas não foi suficientemente estudadas, no que se refere ao seu potencial citotóxico/mutagênico, o qual pode ser monitorado pelo uso do sistema teste de Allium cepa.

Os biomarcadores são úteis e podem ser definidos como sistemas indicadores que geralmente incluem subsistemas de um organismo completo, usados para identificação de um alvo específico (Silva et al., 2003).

Vicentini et al. (2001), relataram que os chás e infusões de plantas medicinais podem conter substâncias tóxicas com efeitos mutagênicos. Por outro lado, o consumo de chás pode suprimir os efeitos de agentes mutagênicos que estejam atuando sobre o organismo humano (Silva et al., 2004).

O método de avaliação de alterações cromossômicas em raízes de Allium é validado pelo Programa Internacional de Segurança Química (IPCS, OMS) e o Programa Ambiental das Nações Unidas (UNEP) como um eficiente teste para análise e monitoramento in situ da genotoxicidade de substâncias ambientais (Cabrera; Rodriguez, 1999).

Sistemas testes vegetais como o de Vicia faba, e principalmente o de Allium cepa, têm sido utilizados para o estudo dos efeitos de extratos vegetais, visando 
a detecção de genotoxicidade (Teixeira et al., 2003; Fachinetto et al., 2007). Esses sistemas também têm importância no monitoramento da poluição ambiental e avaliação do potencial mutagênico de muitos compostos químicos (Ma et al., 1995).

Fiskesjo (1993, 1994), ressaltou a importância e a utilidade de sistemas testes vegetais na avaliação de riscos de genotoxicidade e enfatizou que apesar das diferenças entre os metabolismos de plantas e animais, há também similaridades, e que a ativação de prómutagênicos em plantas possui alta relevância, pois seres humanos consomem plantas tratadas com agentes químicos.

De acordo com a Organização Mundial da Saúde, cerca de $60-80 \%$ da população mundial nos países em desenvolvimento, devido à pobreza e falta de acesso à medicina tradicional, dependem essencialmente de plantas para cuidar de sua saúde. Entretanto, mesmo a diversidade genética vegetal mundial sendo bastante expressiva, poucas espécies (15 a 17\%) têm sido cientificamente estudadas para a avaliação de suas qualidades, segurança e eficácia (Simões et al., 2001; Teixeira et al., 2003; Calixto, 2005; Soares et al., 2006).

Desde os tempos mais antigos, produtos naturais, particularmente aqueles originários de plantas, têm sido uma importante fonte de agentes terapêuticos. Cerca de $25-30 \%$ de todas as drogas disponíveis na terapêutica são derivados de produtos naturais (plantas, microrganismos e animais) (Vicentini et al., 2001; Teixeira et al., 2003; Calixto, 2005).

Os organismos vivos estão freqüentemente expostos à substâncias mutagênicas que podem causar danos celulares. Os danos podem ser induzidos por agentes químicos, físicos ou biológicos que afetam processos vitais como a duplicação e a transcrição gênica, bem como alterações cromossômicas, levando a processos cancerosos e morte celular. Pelo fato de causarem lesões no material genético, essas substâncias são conhecidas como genotóxicas (Costa; Menk, 2000).

Pelo fato de que nos países em desenvolvimento, como o Brasil (Funari; Ferro, 2005), o homem utiliza chás medicinais para o tratamento de doenças, o seu consumo deve ser monitorado, com o objetivo de alertar a população humana sobre os efeitos dos mesmos sobre organismos vivos. Essa revisão, portanto, tem como finalidade informar a respeito da importância do teste de Allium cepa para avaliação preliminar da citotoxicidade/ genotoxicidade de infusões de plantas medicinais.

\section{Efeitos das infusões sobre o ciclo celular de Allium} cepa

O sistema de teste de Allium é bem aceito para o estudo de efeitos de citotoxicidade de plantas medicinais, porque as suas raízes ficam em contato direto com a substância testada, permitindo a avaliação de concentrações diferentes. As alterações cromossômicas e as da divisão das células meristemáticas da raiz de cebola são freqüentemente usados para alertar a população sobre o consumo do produto (Vicentini et al., 2001).

Os efeitos das infusões de plantas medicinais sobre o ciclo celular de Allium cepa têm sido relatados por vários autores (Vicentini et al., 2001; Camparoto et al., 2002; Teixeira et al., 2003; Knoll et al., 2006; Fachinetto et al., 2007), os quais mostraram que os principais efeitos que ocorrem são mutagenicidade e anti-mutagenicidade, bem como aumento e diminuição da proliferação celular de pontas de raízes tratadas com diferentes espécies de plantas medicinais.

A análise de alterações cromossômicas serve como teste de mutagenicidade e é um dos poucos métodos diretos para mensurar danos em sistemas expostos a mutagênicos ou carcinogênicos potenciais. Para possibilitar a avaliação dos efeitos ou danos que agentes mutagênicos podem causar, faz-se necessário que a amostra esteja em constante divisão mitótica, objetivando identificar os efeitos tóxicos e alterações ocorridas ao longo de um ciclo celular, e o teste de Allium cepa tem sido amplamente empregado com esse propósito (Silva et al., 2003). O índice mitótico e índice de replicação são usados como indicadores de proliferação adequada das células (Gadano et al., 2002), o que pode ser medido através do sistema teste vegetal de Allium cepa.

\section{Estudos citogenéticos e o bioteste de Allium cepa}

Os estudos citogenéticos de espécies vegetais informam a respeito de possíveis alterações cromossômicas nas plantas devido à presença de agentes mutagênicos na sua composição ou decorrentes do seu metabolismo. O estudo dos mutagênicos em núcleos eucarióticos vem sendo observado através de métodos citológicos. A mutação pode resultar da ação de compostos químicos, ambientais e radioativos e da estabilidade intrínseca dos ácidos nucleícos. Os agentes mutagênicos podem ser detectados, citologicamente pela inibição do ciclo celular, interrupção em metáfases, indução de alterações cromossômicas numéricas e estruturais e de trocas entre cromátides irmãs entre outros (Vieira; Vicentini, 1997).

Além de sua grande utilização nos testes de citotoxicidade/mutagenicidade de plantas medicinais, o sistema teste de Allium cepa pode ser utilizado para o monitoramento da poluição ambiental e avaliação do potencial mutagênico de muitos compostos químicos. Células meristemáticas de raízes de plantas são indicadores apropriados para a detecção de efeitos clastogênicos causados por poluentes do meio ambiente, especialmente para o monitoramento de contaminantes da água e do solo (Ma et al., 1995). El Shahaby et

Rev. Bras. Farmacogn. Braz J. Pharmacogn 17(3): Jul./Set. 2007 
al. (2003), consideraram o sistema teste de Allium cepa o mais adequado para detecção de toxicidade/ genotoxicidade para avaliação de níveis de poluição ambiental, os quais representam riscos diretos ou indiretos para a população humana.

Grisolia e Takahashi (1990), usaram o sistema teste vegetal de Allium cepa para o estudo dos efeitos de metildopa (droga antihipertensiva), sobre o ciclo celular de cebola, indicando uma diminuição do índice mitótico de Allium cepa em todas as concentrações testadas e também a possível toxicidade da droga.

Utilizando-se de células meristemáticas de Allium cepa, Chauan et al. (1999), estudaram o potencial clastogênico de Cypermethrim e Fenvalerate (pesticidas), sendo que os resultados obtidos pelo sistema teste de Allium cepa teve boa correlação com o sistema teste de mamíferos, indicando o uso do sistema teste de Allium сера como uma alternativa para o monitoramento do potencial genotóxico de vários compostos químicos.

Os testes de citotoxicidade/genotoxicidade realizados pelo sistema teste de Allium cepa baseiam-se em diversos parâmetros de análise, como por exemplo padrões nucleolares atípicos, os quais consistem em um grande número de células com pareamento heteromórfico de nucléolos. O aparecimento de micronúcleos é a conseqüência da quebra cromossômica, evidenciando claramente a manifestação de distúrbios do processo mitótico (Grover; Kaur, 1999).

Entre os testes citogenéticos empregados para avaliação do potencial citotóxico/genotóxico das espécies vegetais destaca-se o sistema teste de Allium cepa (Grant, 1982).

As análises de genotoxicidade de extratos de várias espécies de plantas medicinais têm sido realizadas, tais como: Averrhoa carambola L., Syzygium cumini L. Skeels, Cissus sicyoides L (Vicentini et al., 2001); Maytenus ilicifolia Mart., Bauhinia candicans Benth (Camparoto et al., 2002) Psidium guajava L., Achillea millefolium L. (Teixeira et al., 2003), utilizando-se do teste de Allium cepa, cuja metodologia, consistiu da colocação de bulbos de cebola em água aerada para enraizar em temperatura ambiente. Consideraram o grupo controle como zero hora até a primeira amostra de raiz ser obtida. Estes foram então colocados por 24 horas nos chás preparados na forma de infusão, a partir de espécies medicinais em 02 diferentes concentrações, uma que corresponde aquela geralmente utilizada pelo homem na forma de chá medicinal $(0,07 \mathrm{mg} / \mathrm{mL})$ e outra dez vezes mais concentrada $(0,70 \mathrm{mg} / \mathrm{mL})$, ou colocados em água aerada, consistindo no grupo controle. A seguir, mais algumas radículas foram removidas e os bulbos recolocados em água por 24 horas para observar se houve qualquer recuperação de possíveis danos. As raízes foram fixadas e coradas pela reação de Feulgen e montadas sobre lâminas permanentes. A análise das lâminas foi feita aleatoriamente sem o prévio conhecimento dos tratamentos com objetiva de $40 \mathrm{X}$ em microscópio ótico. Foram analisadas 1000 células por bulbo, totalizando 6000 células do controle, dos tratamentos e das respectivas recuperações. O índice mitótico foi determinado e a análise estatística para comparação dos valores médios dos índices mitóticos foi feita pelo teste $\chi^{2}$.

Knoll et al. (2006), estudaram o potencial genotóxico de diferentes populações de Pterocaulon polystachyum, também através do teste de Allium cepa, utilizando metodologia modificada de Camparoto et al. (2002) e as lâminas foram preparadas pela técnica de esmagamento de acordo com Guerra; Souza (2002). Nesse experimento, evidenciaram a capacidade antiproliferativa de Pterocaulon polystachyum, porque ocorreu a inibição da divisão celular de Allium cepa, conforme o aumento da concentração dos extratos aquosos (chás).

Os testes de citoxicidade utilizando sistema teste vegetal in vivo, como o de Allium cepa, estão validados por vários pesquisadores que realizaram de forma conjunta teste animal in vitro, utilizando células de medula de rato Wistar e os resultados foram similares (Teixeira et al., 2003; Vicentini et al., 2001; Fachinetto et al., 2007). Outros estudos têm sido realizados com o sistema teste vegetal e foi reportado uma concordância entre os sistemas teste vegetal e sistema teste de mamíferos de 75 a 91,5\% (Grant, 1978; Grant,1982; Grover et al., 1990).

Camparoto et al. (2002), obtiveram resultados similares quando avaliaram os efeitos de infusões de Maytenus ilicifolia Mart e Bauhinia candicans Benth em células de Allium cepa e células da medula óssea de ratos Wistar. Os resultados indicaram que o consumo dessas espécies medicinais a partir de infusões pode continuar a ser utilizado pelo homem, no entanto respeitando o método tradicional de preparação, principalmente no que se refere a concentração da infusão.

Os efeitos dos extratos de Psidium guajava L. e Achillea millefolium L. foram avaliados em três sistemas testes: células meristemáticas de Allium cepa, células da medula óssea de ratos e linfócitos humanos, tendo conhecimento de que qualquer substância pode produzir resultados diferentes nos diferentes sistemas testes. Mesmo assim, os resultados antimutagênicos dessas espécies foram observados nos três diferentes sistemas testados (Teixeira et al., 2003), no entanto, os resultados desses estudos não recomendam o consumo de chás feitos dessas plantas, pois as propriedades antimutagênicas específicas de seus compostos não foram aqui definidas. Se o seu uso for necessário, é recomendado nas doses prescritas e não por longo tempo.

\section{CONCLUSÃO}

O sistema teste vegetal de Allium cepa apresenta-se como um bioindicador ideal para o primeiro screening da genotoxicidade de infusões de plantas 
medicinais, devido ao seu baixo custo, confiabilidade e concordância com outros testes de genotoxicidade, auxiliando os estudos de prevenção de danos à saúde humana.

\section{REFERÊNCIAS}

Cabrera GL, Rodriguez DMG 1999. Genotoxicity of soil from farmland irrigated with wastewater using three plant biossays. Mutat Res 426: 211-214.

Chauhan LKS, Saxena PN, Gupta SK 1999. Cytogenetic effects of cypermethrin and fenvalerate on the root meristem cell of Allium cepa. Environ Exp Bot 42: 181-189.

Calixto JB 2005. Twenty-five of research on medicinal plants in Latin America. J Ethnopharmacol 100: 131-134.

Camparoto ML, Teixeira RO, Mantovani MS, Vicentini VEP 2002. Effects of Maytenus ilicifolia Mart. and Bauhinia candicans Benth infusions on onion roottip and rat bone-marrow cells. Genet Mol Biol 25: 85-89.

Costa RMA, Menk CFM. 2000. Biomonitoramento de mutagênese ambiental. Biotecnologia: ciência $e$ desenvolvimento 3: 24-26.

El-Shahaby AO, Abdel Migid HM, Soliman MI, Mashaly IA 2003. Genotoxicity screening of industrial wastewater using the Allium cepa chromosome aberration assay. Pak J Biol Sci 6: 23-28.

Fachinetto JM, Bagatini MD, Durigon J, Silva ACF, Tedesco SB 2007. Efeito anti-proliferativo das infusões de Achyrocline satureioides DC (Asteraceae) sobre o ciclo celular de Allium cepa. Rev Bras Farmacogn 17: 49-54.

Fiskesjo G 1993. The Allium test. In: wastewater monitoring. Environ Toxicol Water Qual 8: 291-298.

Fiskesjo G 1994. The Allium Test II: Assesmente of chemical's genotoxic potential by recording aberrations in chromosomes and cell divisions in root tips of Allium cepa L. Environ Toxicol Water Qual 9: 234-241.

Funari CS, Ferro VO 2005. Uso ético da biodiversidade brasileira: necessidade e oportunidade. Rev Bras Farmacogn 15: 178-182.

Gadano A, Gurni A, López P, Ferraro G, Carballo M 2002. In vitro genotoxic evaluation of the medicinal plant Chenopodium ambrosioides.L. J Ethonopharmacol 81: 11-16.

Grant WF 1978. Chromosome aberrations in plants as a monitoring system. Environ Health Persp 27: 3743.

Grant WF 1982. Chromosome aberrations assay in A report of the U.S. Environmental Protection Agency GeneTox Programme. Mutation Res 99: 273-291.

Grisolia CK, Takahashi CS 1990. Evaluation of mutagenic effect of the antihypertensive drug methyldopa (Aldomet) on mammalian systems in vivo and in vitro and on Allium cepa. Mutat Res 259: 127-132.

Grover IS, Dhingra AK, Adhikari N, Ladhar SS 1990. Genotoxicity of pesticides and systems. Progr Clin Biol Res 340E: 91-106.

Grover IS, Kaur S 1999. Genotoxicity of wasterwater samples from sewage and industrial effluent detected micronucleus assays. Mutat Res 426: 183-188.
Guerra M, Souza MJ 2002. Como observar cromossomos: um guia de técnica em citogenética vegetal, animal e humana. São Paulo, Funpec, 131 p

Knoll MF, Silva ACF, CantoDorow TS, Tedesco SB 2006. Effects of Pterocaulon polystachyum DC. (Asteraceae) on onion (Allium cepa) root-tip cells. Genet Mol Biol 29: 539-542.

Ma TH, Xu Z, Xu C, McConnell H, Rabago EV, Arreola GA, Zhang H 1995. The improved Allium/Vicia root tip micronucleus assay for clastogenicity of environmental pollutants. Mutat Res 334: 185-195.

Silva CR, Monteiro MR, Caldeira-de-Araújo A, Bezerra RJAC 2004. Absence of mutagenic and citotoxic potentiality of senna (Cassia angustifolia Vahl.) evaluated by microbiological tests. Rev Bras Farmacogn 14(Supl. 1): 1-3.

Silva J, Erdtmann B, Henriques JAP 2003. Genética toxicológica. Porto Alegre, Alcance, 422p.

Simões CMO, Schenkel EP, Gossmann G, Mello JCP, Mentz LA, Petrovick PR 2001. Farmacognosia: da planta ao medicamento. 3 ed. Porto Alegre/ Florianópolis: Ed. Universidade/ UFRGS/ Ed. da UFSC.

Soares AKA, Carmo GC, Quental DP, Nascimento DF, Bezerra FAF, Moraes MO, Moraes MEA 2006. Avaliação da segurança clínica de um fitoterápico contendo Mikania glomerata, Grindelia robusta, Copaifera officinalis, Myroxylon toluifera, Nasturtium officinale, própolis e mel em voluntários saudáveis. Rev Bras Farmacogn 16: 447-454.

Teixeira RO, Camparoto ML, Mantovani MS, Vicentini VEP 2003. Assessment of two medicinal plants, Psidium guajava L. and Achillea millefolium L. in in vivo assays. Genet Mol Biol 26: 551-555.

Vicentini VEP, Camparoto ML, Teixeira RO, Mantovani MS 2001. Averrhoa carambola L., Syzygium cumini (L.) Skeels and Cissus sicyoides L.: medicinal herbal tea effects on vegetal and test systems. Acta Scientiarum 23: 593-598.

Vieira D, Vicentini VEP 1997. Estudo do efeito mutagênico do floxacin em Allium cepa. Genet Mol Biol Supplement. $42^{\circ}$ Congresso Nacional de Genética, Goiânia, Brazil. 